DOI: https://doi.org/10.24127/ajpm.v10i1.3388

\title{
PROFIL PEMAHAMAN KONSEP MATEMATIKA DITINJAU DARI SELF EFFICACY
}

\author{
Mida Nurani ${ }^{1}$, Riyadi ${ }^{2}$, Sri Subanti $^{3}$ \\ ${ }^{1,2,3}$ Pendidikan Matematika, Universitas Sebelas Maret, Surakarta, Indonesia \\ E-mail: $\quad$ midanurani2017@gmail.com ${ }^{1)}$ \\ riyadifkipuns@gmail.com ${ }^{2)}$ \\ sri_subanti@yahoo.co.id ${ }^{3}$
}

Received 15 December 2020; Received in revised form 05 March 2021; Accepted 30 March 2021

\begin{abstract}
Abstrak
Tujuan dari penelitian ini adalah mendeskripsikan pemahaman konsep matematika siswa SMA ditinjau dari self efficacy khususnya pada materi matriks. Penelitian ini adalah penelitian deskriptif kualitatif dimana data utama pada penelitian ini adalah hasil tes pemahaman konsep matematika, angket self efficacy dan wawancara. Subjek penelitian yaitu siswa dengan self efficacy tinggi, sedang dan rendah yang kemudian diberi tes pemahaman konsep matematika. Penelitian dilakukan dengan wawancara terhadap hasil tes siswa dan melakukan triangulasi metode. Hasil penelitian ini menunjukkan bahwa pemahaman konsep matematika siswa dengan self efficacy tinggi sudah baik dengan menguasai indikator pemahaman konsep yaitu menyatakan ulang sebuah konsep, mengklasifikasi objek menurut sifat-sifat tertentu, menyajikan konsep dalam berbagai bentuk representasi matematis, menjelaskan keterkaitan antara konsep satu dengan konsep lainnya dan menerapkan konsep dalam pemecahan masalah. Sedangkan siswa dengan self efficacy sedang menguasai indikator menyatakan ulang sebuah konsep, mengklasifikasi objek menurut sifat-sifat tertentu dan menyajikan konsep dalam berbagai bentuk representasi matematis. Dan siswa dengan self efficacy rendah hanya menguasai indikator menyatakan ulang sebuah konsep.
\end{abstract}

Kata kunci: Pemahaman konsep matematika; self efficacy.

\begin{abstract}
The purpose of this study is to describe the understanding mathematics concepts of senior high school students' in term of self-efficacy, especially in matrix. This study is descriptive qualitative that the main data of this study are test, questionnaire, and interview. The research subjects is senior high school students' with many categories such as high, medium, and low in self-efficacy. Then, the researcher give test about the understanding mathematics concepts. The researcher is doing interview and triangulation method to the students. The results of this study indicate that the students' understanding of mathematics concepts with high self-efficacy is good by mastering the conceptual understanding indicators, such as restating a concept, classifying the objects according to specific categories, presenting concepts in various forms of mathematics representation, explaining the relationship between one concept and another concept and applying some concepts in problem solving. Meanwhile, the students with medium self-efficacy are mastering indicators of restating a concept, classifying the objects according to specific categories and presenting concepts in various forms of mathematics representations, and the students with low self-efficacy are only mastering the indicator of restating a concept.
\end{abstract}

Keywords: Self efficacy; understanding of mathematics concepts.

This is an open access article under the Creative Commons Attribution 4.0 International License

\section{PENDAHULUAN}

Belajar matematika merupakan salah satu pembelajaran yang memiliki peran penting dalam kehidupan seharihari. Tujuan utama belajar matematika adalah memecahkan masalah matematika (Christidamayani \& Kristanto, 2020). Dalam memecahkan masalah, matematika lebih banyak memerlukan pemahaman dari pada hapalan. Salah satunya pemahaman konsep matematika. 
DOI: https://doi.org/10.24127/ajpm.v10i1.3388

$\begin{array}{lrr}\text { Pemahaman } & \text { konsep merupakan } \\ \text { unsur penting } & \text { dalam belajar }\end{array}$ matematika. Dengan berbekal pemahaman konsep, siswa dapat menyelesaikan masalah matematika dengan lebih baik. Sebab dalam menyelesaikan masalah, dibutuhkan aturan-aturan. Aturan tersebut didasarkan pada konsep-konsep yang dimiliki (Fajar, Kodirun, Suhar \& Arapu, 2019).

Pemahaman konsep merupakan landasan penting untuk menyelesaikan permasalahan matematika maupun permasalahan dalam dunia nyata (Lestari \& Yudhanegara, 2017). Pemahaman konsep matematika merupakan suatu kemampuan yang menyerap dan memahami ide-ide matematika secara sistematis.

Pemahaman konsep dipengaruhi oleh sekumpulan ide, prosedur, prinsip atau hukum fisik yang dipahami secara holistik dengan relevansi tinggi (Purwanti, Pratiwi \& Rinaldi, 2016). Pemahaman konsep dibentuk secara mandiri oleh siswa, tidak dapat dilakukan hanya melalui transfer ilmu saja (Wardani, 2020). Tetapi siswa diberikan kesempatan yang seluasluasnya untuk membangun sendiri konsep matematikanya melalui pengalaman yang sudah terjadi sebelumnya.

Dalam menyelesaikan masalah matematika, dibutuhkan kemampuan afektif siswa. Hal ini sejalan dengan Masri, Suyono \& Deniyanti (2018) yang menyatakan bahwa kemampuan afektif juga harus dimiliki oleh siswa dalam pembelajaran matematika selain kemampuan kognitifnya. Salah satu kemampuan afektif yang harus dimiliki siswa dalam pembelajaran matematika adalah self efficacy.

Menurut Nahdi (2018) self efficacy adalah kepercayaan atau keyakinan seseorang terhadap kekuatan diri (percaya diri) dalam mengerjakan atau menjalankan suatu tugas tertentu. Namun kenyataannya, seringkali siswa tidak yakin bahwa dirinya mampu menyelesaikan permasalahan yang sedang dihadapi. Sehingga siswa tidak mampu menunjukkan prestasi akademisnya secara optimal sesuai dengan kemampuan yang dimilikinya. Sejalan dengan Fitri (2017) yang menyatakan bahwa self efficacy yang rendah dapat dilihat dari banyaknya siswa yang mengerjakan pekerjaan rumah di sekolah serta menyalin jawaban teman. Selain itu, siswa yang memiliki self efficacy rendah akan mudah menyerah dan cenderung tidak menyelesaikan permasalahan saat dihadapkan dengan permasalahan matematika yang sulit.

Berbeda dengan siswa yang memiliki self efficacy tinggi. Siswa yang memiliki self efficacy tinggi akan merasa tertantang jika diberi permasalahan, terutama permasalahan yang lebih sulit. Siswa dengan self efficacy tinggi akan berusaha keras dalam menyelesaikan permasalahan tersebut. Sejalan pendapat Ghufron \& Risnawati (2014) bahwa dalam situasi sulit, siswa dengan self efficacy rendah akan cenderung menyerah, sedangkan siswa dengan self efficacy tinggi akan berusaha lebih keras untuk mengatasi tantangan. Penelitian lain yaitu Sunaryo (2017) mengungkapkan bahwa adanya self efficacy yang tinggi mendorong siswa untuk tekun serta bersungguhsungguh dalam mempelajari dan mengerjakan tugas-tugas matematika.

Asfar, Asfar, Darmawati \& Darmawan (2018) menyatakan bahwa siswa masih kesulitan memahami konsep matematika. Ketika guru mengubah bentuk tugas, siswa kesulitan dalam memecahkannya. Hal tersebut terjadi karena siswa menghafal rumus 
atau contohnya. Sesuai dengan Kusumaningsih, Darhim, Herman \& Turmudi (2018) bahwa rendahnya pemahaman konsep matematika terjadi karena siswa tidak memahami konsep dalam pembelajaran, melainkan menghafal rumus dan contoh.

Penelitian terkait pemahaman konsep matematika dan self efficacy telah dilakukan beberapa peneliti. Diantaranya Komariyah, Afifah \& Resbiantoro (2018) menyebutkan bahwa pemahaman konsep matematika siswa yang memiliki minat belajar tinggi mampu memecahkan masalah matematika dengan runtut dan benar. Selain itu, penelitian Somawati (2018) mengungkapkan bahwa terdapat pengaruh yang signifikan antara self efficacy terhadap pemecahan masalah matematika.

Rendahnya pemahaman konsep matematika dapat dilihat dari hasil UN siswa SMA Negeri 1 Meraksa Aji tahun 2019 terutama pada materi matriks. Terlihat daya serap siswa hanya mencapai 22,58\%. Selain itu, pemahaman konsep matematika yang rendah juga terlihat dari hasil observasi yang telah dilakukan. Berdasarkan hasil observasi, siswa menghafal contoh yang diberikan oleh guru tanpa memahami konsepnya. Siswa juga tidak yakin dengan kemampuannya, sehingga permasalahan tidak terselesaikan. Oleh karena itu, perlu dianalisis pemahaman konsep matematika siswa SMA Negeri 1 Meraksa Aji khususnya materi matriks berdasarkan self efficacy-nya.

Pemaparan beberapa penelitian dan permasalahan yang telah disajikan yaitu mengaitkan pemahaman konsep matematika dan self efficacy siswa dalam menyelesaikan permasalahan matematika. Sehingga, penelitian ini mengarah pada kebaruan dan orisinalitas berkaitan dengan pemahaman konsep matematika yang ditinjau dari self efficacy siswa. Berdasarkan uraian latar belakang tersebut, maka penelitian ini bertujuan mendeskripsikan pemahaman konsep matematika siswa SMA ditinjau dari self efficacy.

\section{METODE PENELITIAN}

Jenis penelitian ini adalah deskriptif kualitatif. Penelitian dilakukan di SMA Negeri 1 Meraksa Aji yang dilaksanakan pada semester ganjil tahun 2020/2021. Subjek pada penelitian ini adalah siswa kelas XI yang bejumlah 31 siswa. Pemilihan subjek diambil berdasarkan kategori self efficay tinggi, sedang dan rendah dengan seluruh subjek yaitu 9 siswa. Selain itu, pemilihan subjek juga didasarkan atas kemampuan komunikasinya yang baik agar mampu memberikan atau menyampaikan ide dan alasan, sehingga peneliti dapat menggali lebih dalam pemahaman konsep matematikanya.

Instrumen pengumpulan data yang digunakan adalah angket self efficacy, tes pemahaman konsep matematika dan wawancara. Penelitian ini menggunakan triangulasi metode untuk menguji keabsahan data penelitian. Dimana data hasil pekerjaan dan wawancara siswa dikatakan valid jika hasil pekerjaan siswa sesuai dengan hasil wawancara, begitu juga sebaliknya. Langkah pengumpulan data yaitu mengelompokkan subjek penelitian berdasarkan kategori self efficacy tinggi, sedang dan rendah serta memenuhi berdasarkan kriteria yang telah ditentukan. Kemudian melakukan pengambilan data pemahaman konsep matematika siswa dengan cara memberikan tes pemahaman konsep matematika kepada subjek. Untuk memperdalam pemahaman konsep 
matematika subjek, maka dilakukan wawancara terhadap hasil jawaban dan menganalisis data yang diperoleh. Pada tahap akhir disimpulkan hasil analisis pemahaman konsep matematika siswa yang ditinjau dari self efficacy tinggi, sedang dan rendah.

Indikator pemahaman konsep matematika yang digunakan dalam penelitian ini adalah (1) menyatakan ulang sebuah konsep; (2) mengklasifikasi objek menurut sifatsifat tertentu; (3) menyajikan konsep dalam berbagai bentuk representasi matematis; (4) menjelaskan keterkaitan antara konsep satu dengan konsep lainnya dan (5) menerapkan konsep dalam pemecahan masalah (Bardini, Pierce, Vincent \& King, 2014).

Indikator self efficacy yang digunakan dalam penelitian ini adalah indikator self efficacy menurut Bandura (Subaidi, 2016) yang disajikan pada Tabel 1.

Tabel 1. Indikator self efficacy

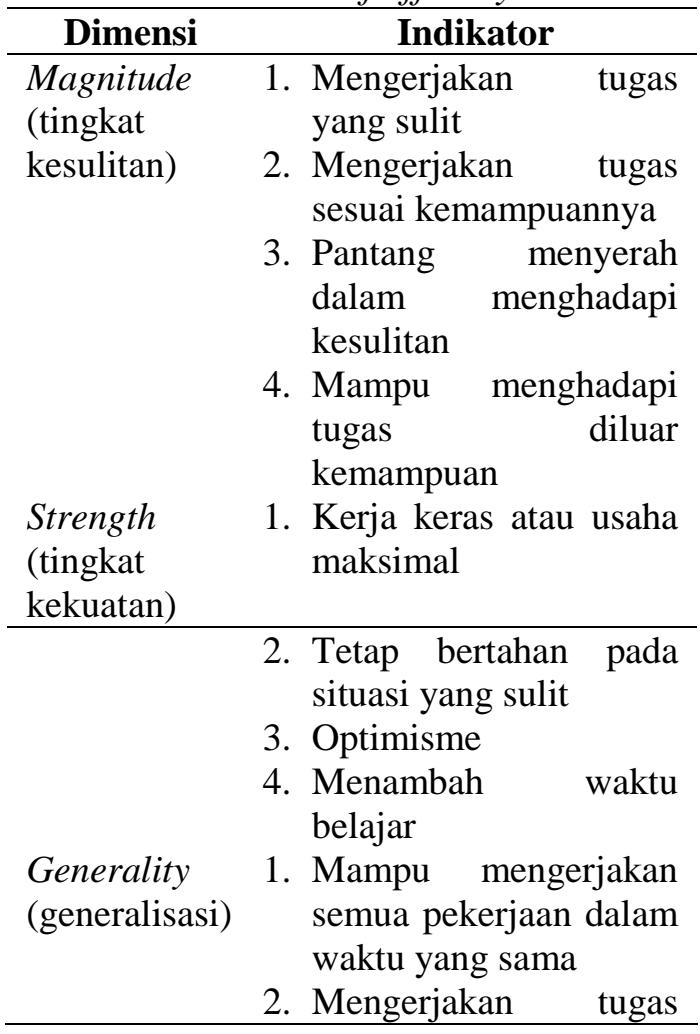

\begin{tabular}{ll}
\hline Dimensi & \multicolumn{2}{c}{ Indikator } \\
\hline & pada bidang yang \\
& berbeda \\
& 3. Menganggap \\
& pengalaman sebagai \\
& dasar meningkatkan \\
& keyakinan \\
\hline
\end{tabular}

Angket self efficacy yang sudah valid dapat digunakan untuk mengukur self efficacy siswa. Angket tersebut diberikan pada siswa SMA Negeri 1 Meraksa Aji kelas XI. Hasil pengukuran self efficacy tersebut dapat dilihat pada Tabel 2.

Tabel 2. Hasil pengukuran self efficacy siswa SMA Negeri 1 Meraksa Aji

\begin{tabular}{|c|c|c|}
\hline \multicolumn{3}{|c|}{$\begin{array}{c}\text { Jumlah Siswa Berdasarkan Kategor } \\
\text { Self Efficacy }\end{array}$} \\
\hline Tinggi & Sedang & Rendah \\
\hline 7 & 15 & 9 \\
\hline $22,58 \%$ & $48,39 \%$ & $29,03 \%$ \\
\hline
\end{tabular}

Berdasarkan hasil pengukuran self efficacy pada tabel 2, selanjutnya dipilih 9 subjek dari kategori tinggi, sedang dan rendah. Selain berdasarkan self efficacy, pemilihan subjek juga dilakukan berdasarkan kemampuan komunikasi siswa. Kemudian memberikan tes pemahaman konsep matematika kepada subjek dan melakukan wawancara atas pekerjaannya. Setelah itu, penarikan kesimpulan dan verifikasi data yang diperoleh akan menjadi temuan baru berupa pemahaman konsep matematika dari masing-masing subjek penelitian.

\section{HASIL DAN PEMBAHASAN}

Data dalam penelitian ini adalah data tes pemahaman konsep matematika dan wawancara. Data tes dan wawancara pemahaman konsep matematika siswa pada kategori self efficacy tinggi, sedang dan rendah disajikan sebagai berikut: 
DOI: https://doi.org/10.24127/ajpm.v10i1.3388

\section{Subjek dengan Self Efficacy Tinggi (S1)}

Hasil tes pemahaman konsep matematika siswa dengan self efficacy tinggi (S1) dapat dilihat pada Gambar 1, 2, dan 3 .

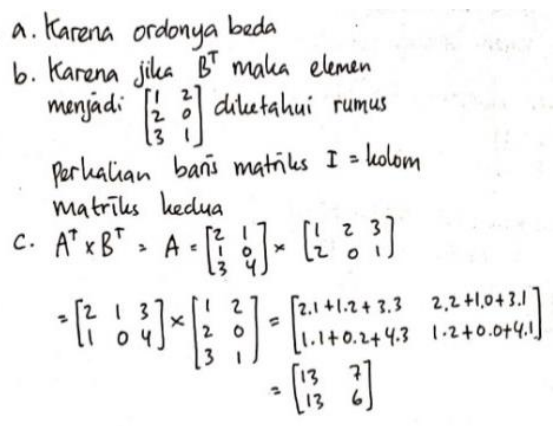

Gambar 1. Jawaban S1 pada tes pemahaman konsep matematika 1

$$
\begin{aligned}
& \operatorname{Det}(p)=\left[\begin{array}{ll}
z & -3 \\
3 & 1-z
\end{array}\right] \\
& \operatorname{det}(p)=z \cdot(1-z)-(-3) \cdot(3) \\
& \operatorname{det}(p)=z-z^{2}+9 \\
& \operatorname{Det}(Q)=\left[\begin{array}{lll}
1 & 0 & -3 \\
2 & z & -6 \\
1 & 3 & 2-5
\end{array}\right] \begin{array}{ll}
1 & 0 \\
2 & z \\
1 & 3
\end{array} \\
& =1 \cdot(z) \cdot z(-5)+0 \cdot(-6) \cdot(1)+(-3)(z)(3)-(1)(z)(-3) \\
& -3 \cdot(-6) \cdot(1)-(z-5) \cdot(2)(0)
\end{aligned}
$$

Gambar 2. Jawaban S1 pada tes pemahaman konsep matematika 2

$$
\begin{aligned}
& \text { Juri I. }=\left[\begin{array}{l}
8 \\
7 \\
10
\end{array}\right], \text { Jur } \mathbb{I}=\left[\begin{array}{l}
8 \\
8 \\
8
\end{array}\right], \text { Jun } \mathbb{T}=\left[\begin{array}{l}
9 \\
8 \\
8
\end{array}\right] \\
& {\left[\begin{array}{l}
8 \\
7 \\
10
\end{array}\right]+\left[\begin{array}{l}
8 \\
8 \\
8
\end{array}\right]+\left[\begin{array}{l}
9 \\
8 \\
8
\end{array}\right]=\left[\begin{array}{l}
25 \\
23 \\
26
\end{array}\right]}
\end{aligned}
$$

Gambar 3. Jawaban S1 pada tes pemahaman konsep matematika 3

Berdasarkan hasil tes dan wawancara yang telah dilakukan terlihat bahwa S1 mampu menyelesaikan seluruh permasalahan matriks dengan tepat. S1 dapat menyatakan ulang sebuah konsep dari penjumlahan maupun perkalian dua matriks, mengklasifikasi determinan ordo 2 x 2 dan determinan ordo $3 \times 3$, menyajikan representasi matematis dari soal cerita kedalam matriks, serta menerapkan konsep penjumlahan dalam pemecahan masalah matriks. Selain itu, S1 juga dapat menjelaskan keterkaitan antara konsep satu dengan konsep lainnya. Dalam hal ini, dapat dimaknai bahwa siswa yang memiliki self efficacy tinggi, tinggi pula pemahaman konsep matematikanya. Sesuai penelitian Rahmi, Febriana \& Putri (2020) bahwa semakin tinggi keyakinan diri (self efficacy) seorang siswa maka akan semakin tinggi pula tingkat pemahaman konsep matematikanya. Sebab self efficacy siswa terhadap matematika adalah kepercayaan diri siswa terhadap kemampuan menyelesaikan permasalahan matematika.

\section{Subjek dengan Self Efficacy Sedang (S2)}

Hasil tes pemahaman konsep matematika siswa dengan self efficacy sedang (S2) dapat dilihat pada Gambar 4,5 , dan 6 .

$$
\begin{aligned}
& \text { A. } A+B\left[\begin{array}{ll}
2 & 1 \\
1 & 0 \\
3 & 4
\end{array}\right]+\left[\begin{array}{lll}
1 & 2 & 3 \\
2 & 0 & 1
\end{array}\right] \text { Tidak bisa dilerenalan } \\
& \text { B. Tidale biste dilergalean karena elemennya berbeda } \\
& \text { C. } A^{\top} \times B^{\top}=A=\left[\begin{array}{ll}
2 & 1 \\
1 & 6 \\
3 & 4
\end{array}\right] \times\left[\begin{array}{lll}
1 & 2 & 3 \\
2 & 0 & 1
\end{array}\right] \\
& =\left[\begin{array}{lll}
2 & 1 & 3 \\
1 & 0 & 4
\end{array}\right] \times\left[\begin{array}{ll}
1 & 2 \\
2 & 0 \\
3 & 1
\end{array}\right]=\left[\begin{array}{ll}
2.1+1.2+3.3 & 2.2+1.0+3.1 \\
1.1+0.2+4.3 & 1.2+0.0+4.1
\end{array}\right] \\
& =\left[\begin{array}{ll}
13 & 7 \\
13 & 6
\end{array}\right]
\end{aligned}
$$

Gambar 4. Jawaban S2 pada tes pemahaman konsep matematika 1

$$
\begin{aligned}
& \text { Alean dicari determinan matriles } \rho \\
& \operatorname{det}(P)=\left[\begin{array}{cc}
z & -3 \\
3 & 1-z
\end{array}\right] \\
& \operatorname{det}(P)=z \cdot(1-z)-(-3) \cdot(3) \\
& =z-z^{2}+9 \\
& \text { Alean dicar deferminan matriles } Q \text { dempan metode } \\
& \text { Sarrus } \\
& \operatorname{det}(Q)=\mid \begin{array}{ccc|cc}
1 & 0 & -3 & 1 & 0 \\
2 & z & -6 & 2 & z \\
1 & 3 & z-5 & 1 & 3
\end{array} \\
& =1 \cdot(z) \cdot(z-5)+0-(-6) \cdot(1)+(-3) \cdot(2) \cdot(3)-(1) \cdot(z)(-3)-(3)(-6) \\
& (1)-(z-5) \cdot(z) \cdot(0) \\
& =z^{2}-5 z+0-18+3 z+18-0 \\
& =z^{2}-2 z
\end{aligned}
$$

Gambar 5. Jawaban S2 pada tes pemahaman konsep matematika 2 
DOI: https://doi.org/10.24127/ajpm.v10i1.3388

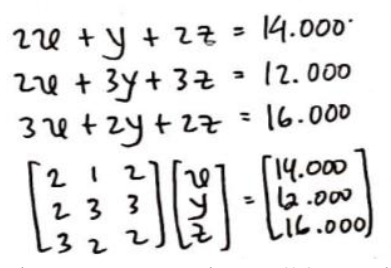

Gambar 6. Jawaban S2 pada tes pemahaman konsep matematika 3

Berdasarkan tes dan wawancara yang dilakukan pada S2 didapat bahwa S2 dapat menyatakan ulang konsep penjumlahan dan perkalian matriks, mengklasifikasi objek menurut sifat determinan ordo $2 \times 2$ dan ordo $3 \times 3$ dan menyajikan model matematika dalam bentuk matriks. Namun S2 ragu dalam menerapkan konsep dalam pemecahan masalah. Hal ini terlihat dari S2 yang tidak melanjutkan penyelesaian setelah menuliskan model matematikanya. Sehingga S2 belum dapat menjelaskan keterkaitan antara konsep satu dengan konsep lainnya. Dalam hal ini, dapat dimaknai bahwa siswa dengan self efficacy sedang, ragu akan kemampuannya dalam menyelesaikan permasalahan. Hal ini bersesuaian dengan penelitian Mardiana, Indrawatiningsih \& Afifah (2018) bahwa siswa dengan self efficacy sedang ragu pada kemampuan yang dimiliki dalam menyelesaikan permasalaan yang diberikan dan menganggap hasil kerjaannya salah.

\section{Subjek dengan Self Efficacy Rendah (S3)}

Hasil tes pemahaman konsep matematika siswa dengan self efficacy rendah (S3) dapat dilihat pada Gambar 7, 8, dan 9 .

Berdasarkan tes dan wawancara yang telah dilakukan, didapat bahwa S3 hanya mampu menyatakan ulang sebuah konsep. Dalam mengklasifikasi objek menurut sifat-sifat tertentu, menyajikan konsep dalam berbagai bentuk representasi matematis, menerapkan konsep dalam pemecahan masalah dan menjelaskan keterkaitan antara konsep satu dengan konsep lainnya belum terpenuhi. Hal ini dapat dilihat bahwa S3 tidak dapat mengklasifikasi determinan ordo $2 \times 2$ dan $3 \times 3$, tidak dapat menyajikan soal cerita kedalam model matematika matriks serta penerapan konsep dalam pemecahannya. Saat S3 merasa tidak mampu menyelesaikan permasalahan yang sulit, maka siswa tersebut tidak mengerjakannya. Sesuai dengan penelitian Mardiana, Indrawatingsih \& Afifah (2018) bahwa siswa dengan self efficacy rendah tidak mampu menyelesaikan permasalahan yang sulit dan cenderung tidak dikerjakan. Dengan demikian, subjek tidak dapat menjelaskan keterkaitan konsep satu dengan konsep lainnya.

A. $A+B$

$$
\begin{gathered}
=\left[\begin{array}{ll}
2 & 1 \\
1 & 0 \\
3 & 4
\end{array}\right]+\left[\begin{array}{lll}
1 & 2 & 3 \\
2 & 0 & 1
\end{array}\right] \text { (Tidah dapat dyawab } \\
\text { harena oddonya hodah farm })
\end{gathered}
$$

B. $A \times B^{+}$

$$
\begin{aligned}
& A \times B^{+} \\
& =\left[\begin{array}{ll}
2 & 1 \\
1 & 0 \\
3 & 4
\end{array}\right] \times\left[\begin{array}{lll}
1 & 2 & 3 \\
2 & 0 & 4
\end{array}\right]=\left[\begin{array}{ll}
1 & 2 \\
2 & 0 \\
3 & 4
\end{array}\right] \\
& =\left[\begin{array}{ll}
2 & 1 \\
3 & 0 \\
3 & 4
\end{array}\right]\left[\begin{array}{ll}
1 & 2 \\
2 & 0 \\
3 & 4
\end{array}\right] \quad \text { TTidak dapas dyawabs } \\
& \text { Marene ordonya hdah ramas }
\end{aligned}
$$

Gambar 7. Jawaban S3 pada tes pemahaman konsep matematika 1

$$
\begin{aligned}
& P \cdot\left[\begin{array}{cc}
2 & -1 \\
3 & z-1
\end{array}\right] \quad q \cdot\left[\begin{array}{lll}
1 & 0 & -3 \\
2 & 2 & -6 \\
1 & 3 & z-5
\end{array}\right] \\
& \text { jawab } \\
& \begin{aligned}
A^{-1} & =\frac{1}{\operatorname{detp}} \operatorname{Adj} P & \begin{array}{l}
\text { Jwab } \\
A^{-1}=\frac{1}{\operatorname{det} q} \operatorname{Adj} q
\end{array} \\
& =\frac{1}{2(z-1) \cdot 3-1}\left[\begin{array}{cc}
z-1 & -1 \\
3 & 2
\end{array}\right] &
\end{aligned} \\
& =\frac{1}{2 z-3}\left[\begin{array}{cc}
z-1 & -1 \\
3 & 2
\end{array}\right] \\
& =\left[\begin{array}{ll}
\frac{z-1}{2 z-3} & \frac{-1}{2 z-3} \\
\frac{3}{z-3} & \frac{2}{z z-3}
\end{array}\right]
\end{aligned}
$$

Gambar 8. Jawaban S3 pada tes pemahaman konsep matematika 2 


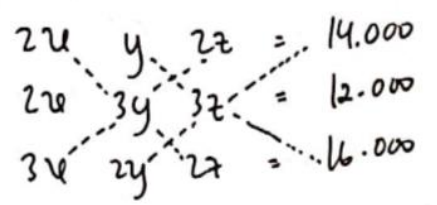

Gambar 9. Jawaban S3 pada tes pemahaman konsep matematika 3

Pemahaman konsep matematika merupakan salah satu kemampuan yang harus dimiliki oleh setiap siswa. Namun kenyataannya pemahaman konsep matematika yang dimiliki oleh siswa masih tergolong rendah. Hal tersebut terlihat dari hasil analisis penelitian ini yang menyimpulkan bahwa siswa hanya mampu menguasai beberapa indikator pemahaman konsep matematika untuk siswa yang memiliki self efficacy sedang dan rendah.

Siswa dengan self efficacy rendah cenderung menyerah dan tidak mengerjakan saat dihadapkan dengan permasalahan matematika yang sulit. Sedangkan siswa dengan self efficacy sedang,ragu akan kemampuannya ketika memecahkan masalah matematika. Sehingga, permasalahan tersebut tidak terselesaikan. Berbeda dengan siswa yang memiliki self efficacy tinggi, siswa dengan self efficacy tinggi lebih mampu menyelesaikan masalah matematika. Hal ini terjadi karena siswa dengan self efficacy tinggi tidak mudah menyerah dan memiliki keyakinan yang tinggi dalam menyelesaikan permasalahan. Sehingga dapat dimaknai bahwa siswa yang memiliki self efficacy tinggi memiliki kemampuan pemahaman konsep yang lebih baik.

Hasil penelitian ini menjadi catatan bagi guru bahwa self efficacy merupakan salah satu kemampuan afektif yang harus dimiliki oleh siswa. Rendahnya self efficacy siswa sejalan dengan rendahya pemahaman konsep siswa terhadap matematika. Oleh karena itu, diharapkan siswa hendaknya memiliki self efficacy yang tinggi. Dalam menumbuhkembangkan self efficacy, guru perlu memahami dan mengembangkan kemampuannya untuk mengarahkan siswanya terhadap kemampuan self efficacy tersebut. Selain itu, guru juga dapat memberikan contoh yang teladan kepada siswa dan memberikan umpan balik yang memperkuat keahlian mereka terutama pemahaman konsep siswa terhadap matematika.

Penelitian ini bersesuaian dengan penelitian Destiniar, Jumroh \& Sari (2019) bahwa terdapat pengaruh kemampuan pemahaman konsep matematis ditinjau dari self efficacy siswa. Siswa yang memiliki self efficacy yang tinggi akan lebih yakin dan berupaya keras untuk menunjukkan hasil terbaik. Selain itu, penelitian Jatisunda (2017) menyebutkan bahwa siswa dengan self efficacy tinggi akan lebih mudah dan berhasil melampaui latihan-latihan matematika yang diberikan padanya. Terlampauianya latihan-latihan tersebut dikarenakan tingginya pemahaman konsep siswa terhadap matematika. Selain itu, penelitian ini memiliki kontribusi untuk memberikan informasi terkait pentingnya self efficacy dalam diri siswa. Dimilikinya self efficacy yang tinggi, maka akan tinggi pula pemahaman konsep matematikanya.

\section{KESIMPULAN DAN SARAN}

Kesimpulan pada penelitian ini adalah siswa yang memiliki self efficacy tinggi menguasai seluruh indikator pemahaman konsep matematika. Hal ini terjadi karena siswa dengan self efficacy tinggi tidak mudah menyerah saat dihadapkan dengan permasalahan yang sulit. Kemudian untuk siswa yang memiliki self efficacy sedang, hanya menguasai indikator menyatakan ulang 
sebuah konsep, mengklasifikasi objek menurut sifat-sifat tertentu dan dan menyajikan konsep dalam berbagai bentuk representasi matematis. Hal ini terjadi karena siswa dengan self efficacy sedang, ragu akan kemampuannya saat dihadapkan dengan permasalahan matematika. Sedangkan siswa dengan self efficacy rendah hanya menguasai indikator menyatakan ulang sebuah konsep. Hal ini terjadi karena siswa dengan self efficacy rendah cenderung tidak mengerjakan saat dihadapkan dengan permasalahan yang sulit.

Saran untuk penelitian selanjutnya yaitu dapat melakukan penelitian tentang kemampuan kognitif lainnya yang ditinjau dari self efficacy. Selain itu, untuk memperdalam informasi dan memmperkuat hasil penelitian dapat dilakukan wawancara terhadap subjek.

\section{DAFTAR PUSTAKA}

Asfar, A. M. I. T., Afsar, A. M. I. A., Darmawati, \& Darmawan, D. (2018). The Effect of REACE (Relating, Exploring, Applying, Cooperating and Evaluaring) Learning Model Toward the Understanding of Mathematics Concept. Journal of Physics: Conference Series, 1028(1). https://doi.org/10.1088/17426596/1028/1/012145

Bardini, C., Pierce, R., Vincent, J., \& King, D. (2014). Undergraduate mathematics students' understanding of the concept of function. Journal on Mathematics Education, 5(2), 85-107. https://doi.org/10.22342/jme.5.2.14 95.85-107

Christidamayani, A. P., \& Kristanto, Y. D. (2020). The effects of problem posing learning model on students' learning achievement and motivation. ArXiv, 2008, 100-108. https://doi.org/10.23917/ijolae.v2i2 .9981

Destiniar, D., Jumroh, J., \& Sari, D. M. (2019). Kemampuan Pemahaman Konsep Matematis Ditinjau Dari Self Efficacy Siswa Dan Model Pembelajaran Think Pair Share (Tps) Di Smp Negeri 20 Palembang. Jurnal Penelitian Dan Pembelajaran Matematika, 12(1). https://doi.org/10.30870/jppm.v12i 1.4859

Fajar, A. P., Kodirun, K., Suhar, S., \& Arapu, L. (2019). Analisis Kemampuan Pemahaman Konsep Matematis Siswa Kelas VIII SMP Negeri 17 Kendari. Jurnal Pendidikan Matematika, 9(2), 229. https://doi.org/10.36709/jpm.v9i2. 5872

Fitri, I. (2017). Peningkatan Self Efficacy Terhadap Matematika Dengan Menggunakan Modul Matematika Kelas Viii Smp Negeri 2 Bangkinang. Jurnal Cendekia: Jurnal Pendidikan Matematika, 1(2), 25-34. https://doi.org/10.31004/cendekia. v1i2. 17

Ghufron, M. N., \& Risnawati, R. (2014). Teori-Teori Psikologi. ArRuzz Media.

Jatisunda, M. G. (2017). Hubungan selfefficacy siswa SMP dengan kemampuan pemecahan masalah matematis. Jurnal Theorems (The Original Research of Mathematics), 1(2), 24-30.

Komariyah, S., Afifah, D. S. N., \& Resbiantoro, G. (2018). Analisis Pemahaman Konsep Dalam Memecahkan Masalah Matematika Ditinjau Dari Minat Belajar Siswa. SOSIOHUMANIORA: Jurnal Ilmiah Ilmu Sosial Dan Humaniora, 4(1), 1-8. 
DOI: https://doi.org/10.24127/ajpm.v10i1.3388

https://doi.org/10.30738/sosio.v4i1 .1477

Kusumaningsih, W., Darhim, Herman, T., \& Turmudi. (2018). Gender differences in algebraic thinking ability to solve mathematics problems. Journal of Physics: Conference Series, 1013(1). https://doi.org/10.1088/17426596/1013/1/012143

Lestari, K. E., \& Yudhanegara, M. R. (2017). Penelitian Pendidikan Matematik. Refika Aditama.

Mardiana, R. E., Indrawatiningsih, N., \& Afifah, A. (2018). Identifikasi Self-Efficacy Siswa MTs dalam Menyelesaikan Soal Cerita Matematika Materi Bangun Ruang Sisi Datar. Jurnal Ilmiah Edukasi \& Sosial, 09(02), 168-173.

Masri, M. F., Suyono, S., \& Deniyanti, P. (2018). Pengaruh Metode Pembelajaran Berbasis Masalah Terhadap Self-Efficacy Dan Kemampuan Pemecahan Masalah Matematis Ditinjau Dari Kemampuan Awal Matematika Siswa Sma. Jurnal Penelitian Dan Pembelajaran Matematika, 11(1). https://doi.org/10.30870/jppm.v11i 1.2990

Nahdi, D. S. (2018). Eksperimentasi Model Problem Based Learning Dan Model Guided Discovery Learning Terhadap Kemampuan Pemecahan Masalah Matematis Ditinjau Dari Self Efficacy Siswa. Jurnal Cakrawala Pendas, 4(1). https://doi.org/10.31949/jcp.v4i1.7 11

Purwanti, R. D., Pratiwi, D. D., \& Rinaldi, A. (2016). Pengaruh Pembelajaran Berbatuan Geogebra terhadap Pemahaman Konsep Matematis ditinjau dari Gaya Kognitif. Al-Jabar: Jurnal Pendidikan Matematika, 7(1),
115-122.

https://doi.org/10.24042/ajpm.v7i1. 131

Rahmi, Febriana, R., \& Putri, G. E. (2020). Pengaruh Self-Efficacy terhadap Pemahaman Konsep Matematika dengan Menerapkan Model Discovery Learning pada Siswa Kelas XI MIA 1 SMA N 5 The Effect of Self-Efficacy on Understanding Mathematical Concepts by Applying the Discovery Learning Model to XI MIA. Jurnal Pendidikan Matematika, 10(April), 27-34. https://core.ac.uk/download/pdf/32 2516050.pdf

Somawati, S. (2018). Peran Efikasi Diri (Self Efficacy) terhadap Kemampuan Pemecahan Masalah Matematika. Jurnal Konseling Dan Pendidikan, $6(1), \quad 39$. https://doi.org/10.29210/118800

Subaidi. (2016). Self-Efficacy Siswa Dalam Pemecahan Masalah Matematika. Jurnal Ligma. Universitas Madura, 1(2), 64-68.

Sunaryo, Y. (2017). Pengukuran SelfEfficacy Siswa Dalam Pembelajaran Matematika di MTs N 2 Ciamis. Teorema, 1(2), 39. https://doi.org/10.25157/.v1i2.548

Wardani, F. (2020). An analysis of student's concepts understanding about simple harmonic motion: Study in vocational high school. Journal of Physics: Conference Series, 1511(1). https://doi.org/10.1088/17426596/1511/1/012079 